\title{
Evidence for close molecular proximity between reverting and undifferentiated cells
}

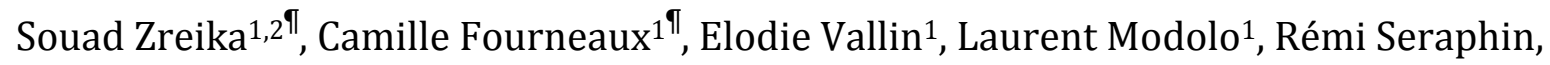
Alice Moussy ${ }^{3}$, Elias Ventre ${ }^{1,4,5}$, Matteo Bouvier ${ }^{1,6}$, Anthony Ozier-Lafontaine ${ }^{7}$, Arnaud Bonnaffoux ${ }^{1,6}$, Franck Picard ${ }^{1}$, Olivier Gandrillon ${ }^{1,4^{\&}}$, Sandrine Giraud ${ }^{1 \text { \&* }}$

1- Laboratory of Biology and Modelling of the Cell, Université de Lyon, Ecole Normale Supérieure de Lyon, CNRS, UMR5239, Université Claude Bernard Lyon 1, Lyon, France.

2- Azm Center for Research in Biotechnology and its Applications, LBA3B, EDST, Lebanese University, Tripoli 1300, Lebanon

3- Ecole Pratique des Hautes Etudes, PSL Research University, UMRS951, INSERM, UnivEvry, Paris, France

4- Inria Team Dracula, Inria Center Grenoble Rhone-Alpes, Grenoble, France

5- Institut Camille Jordan, CNRS UMR 5208, Université Claude Bernard Lyon 1, Villeurbanne, France

6- Vidium solutions, Lyon, France

7- Nantes Université, Centrale Nantes, Laboratoire de mathématiques Jean Leray, LMJL, F-44000 Nantes, France

I These authors contributed equally to this work

$\&$ These authors contributed equally to this work

* Corresponding author: sandrine.giraud@ens-lyon.fr 


\section{Abstract}

According to Waddington's epigenetic landscape concept, the differentiation process can be illustrated by a cell akin to a ball rolling down from the top of a hill (proliferation state) and crossing furrows before stopping in basins or "attractor states" to reach its stable differentiated state. However, it is now clear that some committed cells can retain a certain degree of plasticity and reacquire phenotypical characteristics of a more pluripotent cell state. In line with this dynamic model, we have previously shown that differentiating cells (chicken erythrocytic progenitors (T2EC)) retain for 24 hours the ability to self-renew when transferred back in self-renewal conditions. Despite those intriguing and promising results, the underlying molecular state of those "reverting" cells remains unexplored. The aim of the present study was therefore to molecularly characterize the T2EC reversion process by combining advanced statistical tools to make the most of single cell transcriptomic data. For this purpose, T2EC, initially maintained in a self-renewal medium $(0 \mathrm{H})$, were induced to differentiate for $24 \mathrm{~h}(24 \mathrm{H}$ differentiating cells); then a part of these cells was transferred back to the self-renewal medium (48H reverting cells) and the other part was maintained in the differentiation medium for another $24 \mathrm{~h}$ ( $48 \mathrm{H}$ differentiating cells). For each time point, cell transcriptomes were generated using scRT-qPCR and scRNAseq. Our results showed a strong overlap between $0 \mathrm{H}$ and $48 \mathrm{H}$ reverting cells when applying dimensional reduction. Moreover, the statistical comparison of cell distributions and differential expression analysis indicated no significant differences between these two cell groups. Interestingly, gene pattern distributions highlighted that, while $48 \mathrm{H}$ reverting cells have gene expression pattern more similar to $0 \mathrm{H}$ cells, they retained traces of their engagement in the differentiation process. Finally, Sparse PLS analysis showed that only the expression of 3 genes discriminates $48 \mathrm{H}$ reverting and $0 \mathrm{H}$ cells. Altogether, we show that reverting cells return to an earlier molecular state almost identical to undifferentiated cells and demonstrate a previously undocumented physiological and molecular plasticity during the differentiation process, which most likely results from the dynamic behavior of the underlying molecular network. 


\section{Introduction}

The integration and processing of endogenous and exogenous information constitute a fundamental requirement for cells to ensure functions and survival of unicellular or multicellular organisms. Cellular decision-making is then at the core of the physiological or pathological functioning of living organisms. Early views of the mechanisms governing cell-fate decision-making, and in particular cell differentiation, were based on bulk population data, leading to an over-simplifying deterministic framework. In these first views, cell commitment to a predefined cell-type was thought to be triggered through a stereotyped sequence of intermediate states under the influence of specific signals (1).

Single-cell approaches have allowed to change the scale of observation of many molecular processes and revealed that an important heterogeneity in gene expression lies at the heart of isogenic cell populations $(2,3)$. Stochasticity in gene expression arises from different causes, such as the probabilistic nature of molecular interactions or transcriptional bursts (4). Cell-to-cell variability is visible at all omics levels of gene expression, but is being widely studied at the transcriptomic level since various molecular biology tools are available for this scale of investigation (5). Overall, this heterogeneity in gene expression has been shown to be critical for the process of differentiation, as it provides diversity without the cost of hardwire-encoded fate programs $(6,7)$.

Furthermore, single-cell studies have also enabled the development of stochastic models to describe differentiation from single-cell transcriptomics data. One of the best-known stochastic model is Conrad Waddington's landscape, that also includes the non-genetic part of cell-to-cell heterogeneities (8). According to Waddington's model, the shape of the landscape is determined by Gene Regulatory Networks (GRN) and state transitions are modelled as channelling events: a cell, presented as a ball, starts from a mountain top and crosses valleys before reaching stable state by occupying basins or attractor states, shaped by an underlining GRN (9). Once this stable state is reached, the state potential decreases and the associated cell-fate is restricted or even irreversible (10).

However, it is now clearly accepted that some cells retain fate plasticity $(11,12)$. Under the forced modification of transcription factors stoichiometry, a cell that have reached a differentiated state can return to a more pluripotent stage challenging the classical 
hierarchical view of differentiation $(13,14)$. Quite interestingly, spontaneous fate reversion can be observed under physiological or damaging condition where progenitors or even more committed cells return to an earlier stage, potentially more pluripotent and re-acquire progenitor or stem-cell-like phenotypes and characteristics (15-18). In this view, our recent study has shown that chicken primary erythroid progenitor cells (T2EC) have retained the capacity to go back to self-renewal state for up to $24 \mathrm{H}$ after the induction of differentiation before they irreversibly engaged in the differentiation process (19). Despite intriguing and promising results, the molecular determinants of this so-called fate reversion and the molecular characterization of the reverting cells remain unexplored.

In this work, we go beyond the cellular and phenotypic characterization of the cell reversion process. We characterize the gene expression of primary erythroid progenitors and question if reverting cells undergo an actual fate reversion i.e. in addition to regaining a comparable cellular state, reacquire a molecular state similar to undifferentiated cells.

For this, differentiation of self-renewing cells was induced by medium change during $24 \mathrm{H}$. Then we splitted the differentiating population so that half could pursue differentiation, and the second half was shifted back in self-renewal medium (FIGURE 1). To provide robust quantitative measurements of gene expression variability, we combined a highly sensitive targeted quantification method (scRT-qPCR) with genomewide scRNASeq data to characterize the transcriptome of each population at single cell level: undifferentiated $(0 \mathrm{H})$, differentiating $(24 \mathrm{H}$ and $48 \mathrm{H})$ and reverting $(48 \mathrm{H}$ reverting) cells. Our statistical analyses show that $48 \mathrm{H}$ reverting cells and undifferentiated cells were much more similar, whereas a separation was clearly visible between cells maintained in differentiation ( $48 \mathrm{H}$ differentiating cells) and cells in reversion (48H reverting cells). Furthermore, statistical comparison of cell distributions indicated no significant differences between $0 \mathrm{H}$ cells and $48 \mathrm{H}$ reverting cells. Moreover, gene expression pattern distribution of $48 \mathrm{H}$ reverting cells showed a shift towards expression pattern distribution of $0 \mathrm{H}$ cells. Finally, we identified genes that discriminate $48 \mathrm{H}$ reverting cells and $0 \mathrm{H}$ cells. Using sparse Partial Least Square (20), we were able to show that the expression of 3 genes, HBBA, TBC1D7 and HSP90AA1, was discriminant between $48 \mathrm{H}$ reverting cells and $0 \mathrm{H}$ cells showing that reverting cells kept transcriptional traces of their induction to differentiation. In conclusion, our results 
bioRxiv preprint doi: https://doi.org/10.1101/2022.02.01.478637; this version posted February 3, 2022. The copyright holder for this preprint (which was not certified by peer review) is the author/funder, who has granted bioRxiv a license to display the preprint in perpetuity. It is made available under aCC-BY-NC-ND 4.0 International license.

show that reverting cells display gene expression patterns that are very similar to undifferentiated cells while retaining traces of their response to differentiation induction, which suggests an almost complete molecular reversion after $24 \mathrm{H}$ of differentiation induction. 


\section{Results}

\section{Robustness of single-cell transcriptomics analysis}

We sought to characterize at the molecular level the cells that were induced to differentiate for 24 hours and that retained the ability to proliferate when placed back into self-renewal medium. We used two different complementary single-cell transcriptomic technologies, scRT-qPCR and scRNAseq. scRT-qPCR allows for highly sensitive quantification but is knowledge-driven and offers information of a limited number a genes while scRNAseq, although less precise for low expression level (21), enables genome-wide quantification without prior knowledge. Furthermore, using two different single-cell technologies allowed us to cross validate our observations and point toward robust conclusions.

We first obtained by scRT-qPCR the expression level of 83 genes involved in T2EC differentiation, in $173,173,168,171$ cells for $0 \mathrm{H}, 24 \mathrm{H}, 48 \mathrm{H}$ of differentiation and $48 \mathrm{H}$ reverting cells, respectively. Those genes are known to distinguish cells along the differentiation process and include sterol biosynthesis, metabolism, globin subunits, and transcription factors expressed by erythroid progenitors as published in (19). The robustness of our measurements was confirmed by a Pearson's correlation of 0,85 (pvalue $=2.2 \mathrm{e}-16$ ) between our experiments and the published data (19). To investigate fate-reversion genome-wide by scRNASeq, we adapted the MARSseq protocol ((22) - see material and methods). Then we obtained gene expression levels in 174, 181, 169, 186 single-cells for $0 \mathrm{H}, 24 \mathrm{H}, 48 \mathrm{H}$ of differentiation and $48 \mathrm{H}$ reverting cells, respectively. The concordance between scRT-qPCR and scRNAseq data was confirmed by a Pearson's correlation of 0,73 (p-value $=1,34 \mathrm{e}-13$ ) between the 74 genes common to both datasets.

\section{Similarity between reverting and undifferentiated cells revealed by dimension reduction}

We used UMAP to uncover potential similarities between $48 \mathrm{H}$ reverting cells and subgroups of differentiating cells by projecting the 4 conditions (FIGURE 2: Panel A, scRT-qPCR data and Panel B, scRNAseq data). Then we focused on the normal differentiation process using the 3 times points of differentiation $\mathrm{COH}, 24 \mathrm{H}$ and $48 \mathrm{H}$ differentiating cells) (FIGURE 2: Panel C - H). For both experiments, pairwise representations show that $24 \mathrm{H}$ differentiating cells tend to overlap with both $0 \mathrm{H}$ cells 
(Figure 2: Panel C and D) and 48H differentiating cells (Figure 2: Panel E and F). On the contrary, the undifferentiated cells and $48 \mathrm{~h}$ differentiating cells clearly differ. Interestingly, pairwise representations also reveal that $48 \mathrm{H}$ reverting cells separate well from the $48 \mathrm{H}$ differentiating cells (FIGURE 2: I and J) and from $24 \mathrm{H}$ cells (FIGURE 2: $\mathrm{K}$ and L), but are visually not distinguishable from the $0 \mathrm{H}$ cells (FIGURE 2: M AND N). Almost identical results were observed when, instead of plotting cells on the UMAPs calculated from the mix of the 4 conditions, we recalculated the UMAPs for each pair of conditions (Supplementary 1). Those analyses suggest that the transcriptomes of $48 \mathrm{H}$ reverting cells are more similar to the undifferentiated cells than to any other condition at both scales of observation. This was further confirmed by the pairwise statistical comparison of average scRNAseq distributions ((23) - see material and methods). As shown in Table 1 , the average transcriptomes of $48 \mathrm{H}$ reverting and $48 \mathrm{H}$ differentiating cells are significantly different, as well as of undifferentiated and $48 \mathrm{H}$ differentiating cells. In contrast, no significant difference in average transcriptomes was detected between $0 \mathrm{H}$ and $48 \mathrm{H}$ reverting conditions ( $\mathrm{p}$-value $>>0.05$ ), indicating a very close proximity of $48 \mathrm{H}$ reverting cells to undifferentiated cells.

\section{H reverting cells and undifferentiated cells have similar gene expression patterns}

We then questioned if $48 \mathrm{H}$ reverting cells had gene expression patterns identical to $0 \mathrm{H}$ cells or retained, for some genes, an expression pattern more similar to $24 \mathrm{H}$ or $48 \mathrm{H}$ differentiating cells.

Pairwise scRNAseq DE analysis revealed that the "normal" erythrocyte differentiation process showed an increase in the expression of hemoglobin related genes during the kinetics (Hemoglobin subunit epsilon 1 (HBBA), Hemoglobin Alpha-Locus 1 (HBA1), and Hemoglobin Alpha, subunit D (HBAD)) (FIGURE 3: panel A, B and C). On the other hand, $0 \mathrm{H}$ cells expressed high level of $L D H A$ (Lactate Dehydrogenase A), marker for glycolysis metabolism used by self-renewing cells (24) and ID2 (Inhibitor Of DNA Binding 2) coding for a transcription factor involved in differentiation inhibition (25).

Interestingly, when comparing $0 \mathrm{H}$ with $48 \mathrm{H}$ reverting cells, we saw only one gene that was significantly differentially expressed just above the threshold (FIGURE 3: panel D), the RSFR (RNase Super Family Related) gene, that is highly expressed in precursor cells from chicken bone marrow (26). Furthermore, when comparing $48 \mathrm{H}$ reverting with $48 \mathrm{H}$ 
differentiating cells, we found hemoglobin related genes up in the differentiating cells and $L D H A$ and ID2 up in reverting cells (FIGURE 3: panel E).

We more closely investigated gene expression distributions within the different conditions to see how gene expression patterns would evolve during the reversion process (FIGURE 4). We selected 8 genes differentially expressed and which expression increases or decreases during the differentiation process. $H B A 1, H B B A, H B A D$ (different hemoglobin subunits) and FECH (Ferrochelatase) are involved in hemoglobin and heme pathways and are more expressed by differentiating cells while LDHA, ID2, CSTA (cystatin A1) and CRIP1 (Cysteine-rich intestinal protein1) are more expressed by selfrenewing undifferentiated cells. We plotted and compared their distribution between the 4 conditions. For the genes involved in differentiation, we see a gradual shift in the distributions towards a higher level of expression as cells get more differentiated (FIGURE 4: Panel A - D) and we see the opposite shift for genes involved in proliferation (FIGURE 4: Panel E - H). In all cases, the 48H reverting cell expression patterns for those genes shifted back to patterns closer to the $0 \mathrm{H}$ cells. At the time of observation and especially for genes up in differentiation, the $48 \mathrm{H}$ reverting cell expression patterns are not completely similar to those of $0 \mathrm{H}$ cells. This was further confirmed by using a dedicated statistical tool, Sparse PLS (see below).

To go further on gene distribution comparisons we computed Wasserstein distances, a geometric distances well suited for comparing multimodal distributions, for each 2000 genes of the scRNAseq dataset between each condition two by two. We then obtain 6 distributions of Wasserstein distance values. Finally, we computed the Gini index as a measure of statistical dispersion in each distribution (the higher the Gini index is, the higher inequality among the values). We performed 100 bootstraps and compared the Gini values obtained (FIGURE 5A). Distribution of Wasserstein distances between $0 \mathrm{H}$ cells and $48 \mathrm{H}$ reverting cells had the smallest average Gini index among all distributions (Figure 5B). This result points towards a closer global transcriptional state between $48 \mathrm{H}$ reverting cells and $0 \mathrm{H}$ cells.

\section{H reverting cells retain molecular traces of a commitment into differentiation}

To further characterize the molecular changes that persisted after reversion, we sought to identify predictive genes that discriminate the most the $48 \mathrm{H}$ reverting cells and the 
undifferentiated cells. We performed logistic regression combined with dimension reduction (Partial Least Square (20)) between $48 \mathrm{H}$ reverting cells and $0 \mathrm{H}$ cells and retained common most discriminating genes between scRT-qPCR and scRNAseq datasets. Interestingly, our results showed that only 3 common genes discriminate between the two cell groups: $H B B A, T B C 1 D 7$ and $H S P 90 A A 1$, the expression of which is shown in FIGURE 6. HBBA is a subunit of the hemoglobin complex which carries oxygen, TBC1D7 is presumed to have a role in regulating cell growth and differentiation (27) and HSP90AA1 codes for an isoform of the HSP90 protein chaperone, which its specific transcription is known to be induced in response to insulin (28). Looking closely, the $48 \mathrm{H}$ reverting cells have an intermediate expression level between differentiating cells and undifferentiated cells for the three predicted genes. The offset observed could be due to a longer duration of mRNA half-life at $24 \mathrm{H}$ of differentiation. We had previously performed a quantification of mRNA half-life during avian erythrocyte differentiation ((29) Supplementary 2). We focused on mRNA half-life at $24 \mathrm{H}$ for those three genes. TBC1D7 and HSP90AA1 have a relatively short half-life as opposed to HBBA. Other genes analyzed whose expression increases during differentiation, such as DPP7, TPP1 or $R P L 22 L 1$ have also a long half-life duration mRNAs, but only $H B B A$ was identified in our statistical analysis as discriminating between undifferentiated and $48 \mathrm{H}$ reverting cells.

These results confirmed that the $48 \mathrm{H}$ reverting cells display a gene expression pattern very close to those of $\mathrm{OH}$ cells while still retaining traces of their engagement into the differentiation process independently of the mRNA half-life. The molecular process explaining such "lagging genes" will have to be explored.

\section{Cells are distributed as a continuum along the differentiation path}

At that stage, two hypotheses could be made: 1 . Either all cells have engaged into a differentiation process, and do molecularly revert to a self-renewal transcriptional state or 2. At $24 \mathrm{H}$ of differentiation two subpopulations coexist: one that is still undifferentiated and would give rise to the $48 \mathrm{H}$ reverting cells and a second more differentiated which would lead to the $48 \mathrm{H}$ differentiating population and die in the reversion experiment.

We hypothesized that the existence of two subpopulations at 24 hours should lead to a higher number of modes in the distribution of some genes at that time point. To test this hypothesis, we therefore estimated for each condition the most-likely number of modes 
for the probability distribution of each gene, as assessed through a Gamma mixture on scRNAseq (see material and methods). We found no significant difference in the number of modes observed between the 4 populations (Figure 7), which confirms that the cells collected from $24 \mathrm{H}$ do not show more multi-stability than the other groups, and are thus unlikely to be a mix of two populations.

The second hypothesis would also imply that in the $24 \mathrm{H}$ population the cells engaged too far in the differentiation process would die a short time after media was changed, while only the undifferentiated ones would survive. We then measured the viability rate during the kinetics and found no difference in viability between the conditions and especially between the $24 \mathrm{H}$ differentiation and the $48 \mathrm{H}$ reversion conditions (Supplementary 3).

Finally, the second hypothesis would also imply that the reversion cells are simply cells that have not entered the differentiation process. It would therefore be at odds with the evidence that the $48 \mathrm{H}$ reverting cells display slightly different pattern of gene expression as $\mathrm{OH}$ cells, but do retain traces of their engagement into the differentiation process (see upper).

Those results strongly suggest that the $24 \mathrm{H}$ cell population is not composed of two coexisting subpopulations of cells and that $48 \mathrm{H}$ reverting cells enter differentiation before going back to a transcriptomic state close to $0 \mathrm{H}$ cells. 


\section{Discussion}

In the present study, we couple two different single-cell transcriptomic techniques and state-of-the-art statistical approaches to demonstrate the fate reversibility of avian erythrocyte progenitors induced to differentiate for 24 hours.

Our results show a very close proximity of reverting and undifferentiated cell transcriptomes. Indeed, statistical comparison of cell distributions showed no significant difference between $0 \mathrm{H}$ and $48 \mathrm{H}$ reverting cells while, as expected, significant changes in gene expression accompanied the differentiation sequence. The analysis of gene expression distribution patterns of the $48 \mathrm{H}$ reverting cells confirmed a switch toward the $0 \mathrm{H}$ cells gene expression profiles. First, DE analysis of scRNAseq data showed only one gene significantly differentially expressed between the two conditions. Second, Wasserstein distance analysis revealed closer distances between $48 \mathrm{H}$ reverting and $0 \mathrm{H}$ cells than to any other group of cells. Third, Sparse PLS analysis indicated that the expression level of only three gene, $H B B A, T B C 1 D 7$ and $H S P 90 A A 1$, was predictive of the $48 \mathrm{H}$ reverting and undifferentiated cells. Interestingly the persistence of those three genes in $48 \mathrm{H}$ reverting cells does not seem to be caused by mRNA half-life duration.

All of our results therefore favor the hypothesis that a vast majority of the $48 \mathrm{H}$ reverting cells responded to differentiation induction by modifying their gene expression profiles but then returned to the self-renewal transcriptional state.

One must note that this would not be the sole example of large scale transcriptomic changes on (relatively) short time scales $(18,30)$. The question as to whether such largescale transcriptome changes are accompanied, or not, by (reversible) large scale epigenetic changes remains an open question for future studies.

It has been described in the literature that during cellular decision making, the cell state is maintained by dynamic interactions between positive and negative regulatory molecules (31) within the frame of a Gene Regulatory Network (GRN). These interactions can be repurposed by changing the stoichiometry of ubiquitous and specific regulatory molecules and factors $(11,32)$. In our study, the analysis of gene expression patterns during the reversion process confirmed that the determination of the fate of erythrocyte progenitors is directed by the constraints of the dynamics of the GRN, influenced by signals emitted by changing conditions of the environment surrounding the cells. In the absence of differentiation signals (or in the presence of self-renewal 
inducing signals), there is no ratchet in place that would prevent (at least at early stages in our case) the system to return back to its original quasi-steady state. This is in excellent agreement with the previous demonstration that there is a duration threshold for some GRN under which the systems can return back to its original state (33). This was proposed to allow cells to discriminate between bona fide signals and random noise in their environment, and could represent a physiological system for finely tuning the in vivo production of red blood cells while preserving the pool of progenitors. We recently proposed a methodology for inferring the GRN underlying T2EC differentiation (29). For that we kept in silico cells under constant differentiation stimulus. It would be of interest to see if the inferred GRN would be able to revert, up to a certain point where no "spontaneous" return is possible (19), to its original state. This would be a very strong constraint to impose and should severely limit the number of putative GRN able to reproduce experimental data and thus approaching the most accurate network.

Taken together, our results point towards a physiological plasticity and reversibility with respect to erythrocyte decision-making. It is also reminiscent of the plasticity observed in Cancer Stem Cells that might not be specific to tumour cells (34). In terms of epigenetic landscape, our work implies that instead of a continuous gradient that the cells will roll down as in the classical Waddington's depiction (8), they may go through an unstable state and may, sometimes, roll upwards over a bump in the landscape (35). Thus, differentiation should be more appropriately described as cells moving from well to well, that is, from one metastable state (36-38) to another one (Figure 8). This view abides by the multi-stability framework where a complex quasi-potential landscape aims at describing both normal and pathological differentiation processes $(39,40)$, and exemplifies the fact that "commitment (is) a dynamical property of the landscape" (41). It is important at this stage to remember that Waddington himself was aware that his drawing was but a simplification. Adapting and refining this landscape should not be considered as departing from his views. Such a non-monotonous landscape has been proposed to account for the depiction of regeneration in adult tissues (42), and is consistent with previously proposed dynamical principles of cell fate restriction (10). It is in excellent accordance with the recent depiction that cells can "climb uphill on Waddington's epigenetic landscape" during cranial neural crest cells development (15), and would also be more relevant to account for the « hesitant » behavior of human CD34 stem cells in vitro (43) than a straight slope. It is beyond the scope of this discussion to 
go into more details, but a cell "climbing uphill" should be seen as equivalent as "the landscape bending into a new valley".

In conclusion, our work has provided a detailed molecular characterization of the probabilistic nature of erythrocyte cell fate determination, influenced by the constraints of the underlying Gene Regulatory Network dynamics, and driven by environmental influences. These new insights into the process of cell reversion could also lead to significant improvements of the executable GRN inference scheme (29). 


\section{Material and methods}

\section{Cellular biology}

T2EC were extracted from bone marrow of 19-d-old SPAFAS white leghorn chicken's embryos (INRA, Tours, France). Cells were grown in self-renewal in LM1 medium ( $\alpha$ MEM, 10\% Foetal bovine serum (FBS), 1 mM HEPES, $100 \mathrm{nM} \beta$-mercaptoethanol, $100 \mathrm{U} /$ $\mathrm{mL}$ penicillin and streptomycin, $5 \mathrm{ng} / \mathrm{mL}$ TGF- $\alpha, 1 \mathrm{ng} / \mathrm{mL}$ TGF- $\beta$ and $1 \mathrm{mM}$ dexamethasone) as previously described (44).

Differentiation was induced by removing LM1 medium and placing the cells into DM17 medium ( $\alpha$-MEM, 10\% foetal bovine serum (FBS), $1 \mathrm{mM}$ Hepes, $100 \mathrm{nM} \beta$ mercaptoethanol, $100 \mathrm{U} / \mathrm{mL}$ penicillin and streptomycin, $10 \mathrm{ng} / \mathrm{mL}$ insulin and 5\% anemic chicken serum (ACS; (45)).

Differentiation kinetics were achieved by collecting a sub fraction of the cells at different times after induction of differentiation $(0 \mathrm{H}$ and $24 \mathrm{H})$. After $24 \mathrm{H}, \mathrm{DM} 17$ medium was removed and half of the cells were placed back into LM1 medium while the other half was kept in DM17 medium to achieve $48 \mathrm{H}$ revertion and $48 \mathrm{H}$ differentiation time points respectively (FIGURE 1).

Cell population mortality was assessed by counting dead and living cells from the different time points and conditions after Trypan blue staining and using a Malassez cell.

\section{Single-cell sorting}

Single-cells were sorted using a FACS Aria II $\mu$, BD. We collected around 200 cells per time point (8 plates) for each experiment (scRT-qPCR and scRNAseq, see below).

\section{Single-cell RT-qPCR analysis}

All the manipulations related to the high-throughput scRT-qPCR experiments in microfluidics were performed according to the protocol recommended by the Fluidigm company (PN $68000088 \mathrm{~K} 1, \mathrm{p} .157-172$ ). All steps from single-cell isolation to scRTqPCR, genes selection, data generation and cleaning are described in detail in (19). Expression matrix was $\log 1 \mathrm{p}$ transformed before subsequent analysis. 


\section{Single-cell RNAseq}

scRNAseq was performed using an adapted version of MARSseq protocol (Massively parallel single-cell RNA sequencing) (22). Unless specified, all indicated concentrations correspond to final concentrations.

Individual cells were sorted into 96-well plates containing $4 \mu \mathrm{L}$ of lysis buffer and index RT primers (0,2\% Triton (Sigma Aldrich), 0,4 U/ $\mu \mathrm{L}$ RNaseOUT (Thermofisher Scientific), 400nM RT_primers (Sigma Aldrich)). Index RT_primers (Table 1) contain oligo-dT chain to capture mRNA, a T7 RNA polymerase promoter for further in vitro transcription (IVT), unique cell barcodes for subsequent de-multiplexing and unique molecular identifiers (UMIs) for PCR bias deduplication. After cell sorting, plates were immediately centrifuged and frozen on dry ice before storage at $-80^{\circ} \mathrm{C}$ until reverse transcription (RT) was performed. The plates were put at $72^{\circ} \mathrm{C}$ for 3 minutes for denaturation. $4 \mu \mathrm{L}$ of RT mix were added in each well (2mM dNTP (Thermo scientific), 20mM DTT, 2X First stranded buffer, $5 \mathrm{U} / \mu \mathrm{L}$ Superscript III RT enzyme (Superscript III RT enzyme kit Thermo scientific), 10\% (W/V) PEG 8000 (Sigma Aldrich)). ERCC RNA spike-in (Thermo Scientific) were diluted into the RT mix (dilution $5 \times 10^{-7}$ ). The plates were then transferred into a thermocycler (program: $42^{\circ} \mathrm{C}-2 \mathrm{~min}, 50^{\circ} \mathrm{C}-50 \mathrm{~min}, 85^{\circ} \mathrm{C}-5 \mathrm{~min}, 4^{\circ} \mathrm{C}$ hold).

After reverse transcription, samples were pooled by plate and ExonucleaseI (NEB) digestion was performed, followed by 1,2X AMpure beads purification (Beckman Coulter). Samples were eluted in $10 \mathrm{mM}$ Tris-HCl, $\mathrm{pH}=7,5$. Second strand cDNA synthesis was performed with 1X SSS buffer and SSS enzyme (NebNext mRNA second strand synthesis kit NEB; thermocycler program: $16^{\circ} \mathrm{C}-150 \mathrm{~min}, 65^{\circ} \mathrm{C}-20 \mathrm{~min}, 4^{\circ} \mathrm{C}$ hold). Resulting double strand cDNA were linearly amplified by IVT overnight (10mM ATP, 10mM GTP, 10mM UTP, 10mM GTP, 1X reaction buffer, 1/10 T7 RNA polymerase mix (HighScribe T7 High Yield RNA synthesis NEB)) at $37^{\circ} \mathrm{C}$. IVT products were purified with 1,3X Ampure beads and eluted with 10mM Tris-HCl, 0,1mM EDTA. Amplified RNAs were fragmented (1X RNA fragmentation buffer (RNA fragmentation reagents Invitrogen)) at $70^{\circ} \mathrm{C}$ for $3 \mathrm{~min}$. The fragmentation reaction was stopped with $34 \mu \mathrm{L}$ of STOP mix $(0,3 \mathrm{X}$ Stop solution (RNA fragmentation reagents Invitrogen), TE buffer $1 \mathrm{X}$ (10mM Tris, 1mM EDTA, pH 8 - Invitrogen) and 0,7X AMpure beads to procede with sample purification). Differing from original MARSseq protocol, instead of ligation, a second RT was done to incorporate P5N6 primers (Table 2) containing random hexamers and specific barcodes 


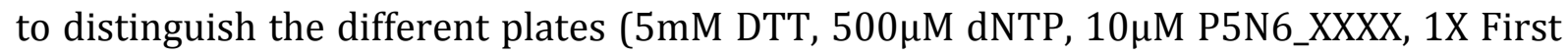
stranded buffer, 10U/ $\mu \mathrm{L}$ Superscript III RT enzyme, 2U/ $\mu \mathrm{L}$ RNaseOUT; thermocycler program: $25^{\circ} \mathrm{C} 5 \mathrm{~min}, 55^{\circ} \mathrm{C} 20 \mathrm{~min}, 70^{\circ} \mathrm{C} 15 \mathrm{~min}, 4^{\circ} \mathrm{C}$ hold). The cDNAs were then purified with 1,2x AMpure beads. Illumina primers (Table 1) were added by PCR (0,5 $\mu \mathrm{M}$ Mix primer P5.rd1/P7.Rd2, 1X KAPA Hifi HotStart PCR Mix (Kapa Biosystem); thermocycler program: $95^{\circ} \mathrm{C} 3 \mathrm{~min}, 12$ times $\left[98^{\circ} \mathrm{C} 20 \mathrm{sec}, 57^{\circ} \mathrm{C} 30 \mathrm{sec}, 72^{\circ} \mathrm{C} 40 \mathrm{sec}\right], 72^{\circ} \mathrm{C} 5 \mathrm{~min}, 4^{\circ} \mathrm{C}$ hold), and PCR products were purified with 0,7x AMpure beads and eluted in $15 \mu \mathrm{L}$.

Libraries were sequenced on a Next500 sequencer (Illumina) with a custom paired-end protocol to avoid a decrease of sequencing quality on read1 due to high number of $\mathrm{T}$ added during polyA reading (130pb on read 1 and $20 \mathrm{pb}$ on read2). We aimed for a depth of 200000 raw reads per cell.

\begin{tabular}{|l|l|}
\hline Primer Name & 5' to 3' $^{\prime}$ \\
\hline $\begin{array}{l}\text { Index_RT_primers } \\
\text { (cell BC and UMI) }\end{array}$ & $\begin{array}{l}\text { 5'-CGATTGAGGCCGGTAATACGACTCACTATAGGGGCGACG } \\
\text { TGTGCTCTTCCGATCTXXXXXXNNNNNNNNTTTTTTTTTTTTTTTTTTTTV-3' }\end{array}$ \\
\hline $\begin{array}{l}\text { P5N6_XXXX } \\
\text { (Plate BC) }\end{array}$ & $\begin{array}{l}\text { 5'-CTACACGACGCTCTTCCGATCTXXXXNNNNNN-3' } \\
\text { P5.rd1 }\end{array}$ \\
\hline P7.rd2 & $\begin{array}{l}\text { 5'-CAATGCACGACGCTCTTCCGATCT-3' } \\
\text { GTGACTGGAGTTCAGACGTGTGCTCTTCCGATCT-3' }\end{array}$ \\
\hline
\end{tabular}

Table 2: List and sequences of primers used for scRNAseq libraries construction.

\section{Bio-informatic pipeline}

Fastq files were pre-processed through a bio-informatic pipeline developed in the team on the Nextflow platform (46). Briefly, the first step removed Illumina adaptors. The second step de-multiplexed the sequences according to their plate barcodes. Then, all sequences containing at least 4T following cell barcode and UMI were kept. Using UMItools whitelist, the cell barcodes and UMI were extracted from the reads. The sequences were then mapped on the reference transcriptome (Gallus GallusGRCG6A.95 from Ensembl) and UMI were counted. Finally, a count matrix was generated for each plate.

\section{Data filtering, normalization and analysis}


All analysis were carried out using R software $(4.0 .5 ;(47))$. Matrixes from the eight plates were pooled together. Cells were filtered based on several criteria: reads number, genes number, counts number and ERCC content. For each criteria the cut off values were determined based on SCONE (48) pipeline and were calculated as follows:

$$
\text { mean }-3^{*} \text { sd }
$$

We selected genes present in at least two cells. Filtered matrix was then normalized using SCTransform from Seurat package (49) and we corrected for batch effect, time effect and sequencing depth effect. Expression matrix was finally $\log 1 \mathrm{p}$ transformed.

Variable genes were identified using FindVariableFeatures from Seurat, vst method (50). Based on visualization of genes variance, we retained the 2000 most variable features. Differentially expressed genes were identified using FindMarkerGenes function from Seurat (50). Analysis was by pairwise comparisons between conditions, genes with log fold change $>=0,5$ and adjusted $p$-value $<0,05$ were kept as significant. More information on QC filtering are given in Supplementary 4.

\section{Statistical analysis}

All statistical analyses were performed using the $\mathrm{R}$ software (4.0.5; (47)). Dimensionality reduction and visualization were performed using UMAP (51). Adaptive Sparse PLS for Logistic Regression was performed using the plsgenomics package (20). For this analysis, scRT-qPCR data were scaled. Sparse PLS is a supervised statistical analysis that allow to predict the most discriminant variables between two groups.

Wasserstein distance computation was done using the Transport R package (52), and was accomplished for each gene of the scRNAseq dataset.

Gini indexes were calculated using the Ineq $\mathrm{R}$ package on Wasserstein distance distributions (53).

Bootstraping was done using sample_frac function from Dplyr R package(54).

\section{Estimation of multi-stability levels}

For estimating the level of multi-stability in the data, we considered that the probability distribution of each gene can be approximated by a Gamma distribution, or a mixture of Gamma distributions, since they are known to describe continuous single-cell data accurately (55). More precisely, we parameterized the distribution of a gene $i$ by: 


$$
p_{i}^{m}(x)=\sum_{j=1}^{m} \mu(j) \frac{x^{a_{i}^{j}-1} b_{i}^{a_{i}^{j}} e^{-b_{i} x}}{\Gamma\left(a_{i}^{j}\right)},
$$

Where $\Gamma$ denotes the Gamma function: $\Gamma(z)=\int_{o}^{\infty} t^{z-1} e^{-t} d t$. Note that only the parameters $\left(a_{i}^{j}\right)_{j=1, \ldots, m}$ depend on the mixture component $j$ : this is related to the distribution arising from the well-established two-states model of gene expression (56), when only the frequency of mRNA bursts is regulated, as described in (57).

For every condition, we constructed 10 training sets consisting of $80 \%$ of the cells in the population (randomly-chosen), and we estimated the parameters $\left[\left(a_{i}^{j}\right)_{j=1, \ldots, m}, b_{i}\right]$ with a MCMC algorithm for the numbers of mixture components $m=1,2,3$ successively. We then considered that the optimal number of components for gene $i$ was the one which minimized the average BIC score estimated on the 10 corresponding test sets.

\section{Multivariate two-sample test}

Samples were compared using a multivariate two-sample test based on the 2000 most variable genes. We suppose that the normalized gene expression $X_{1}$ and $X_{2}$ of two conditions $(0 \mathrm{H}$ vs $48 \mathrm{H}$ reversion, $0 \mathrm{H}$ vs $48 \mathrm{H}$ differentiation, $48 \mathrm{H}$ reversion vs $48 \mathrm{H}$ differentiation), follow a multivariate Gaussian distribution $\mathcal{N}\left(\mu_{1}, \Sigma\right)$ and $\mathcal{N}\left(\mu_{2}, \Sigma\right)$ respectively, and we denote by $n=n_{1}+n_{2}$ the total number of cells. Then we test the null hypothesis $H_{0}: \mu_{1}=\mu_{2}$ using the generalized Hotelling's $T^{2}$ test (23). The data being high dimensional $(p>n)$, the between-gene pooled covariance matrix is not invertible, and is replaced by its Moore-Penrose inverse. In this setting the asymptotic distribution of the generalized Hotelling statistics is $\chi^{2}(n-2)$. The p-values were adjusted according to the Benjamini-Hochberg correction (58). Analysis was performed using the fdahotelling R package (59).

\section{Code and data availability}

Pipelines and analysis scripts are available at https://gitbio.enslyon.fr/LBMC/sbdm/mars_seq. scRT-qPCR data are available at https://osf.io/upw8d/. scRNAseq data are available at http://www.ncbi.nlm.nih.gov/bioproject/802343 BioProject ID PRJNA802343. 


\section{Figures}

OH CELLS
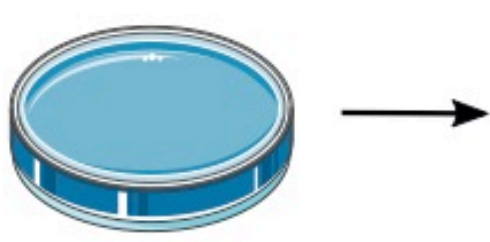

24H DIFFERENTIATING CELLS
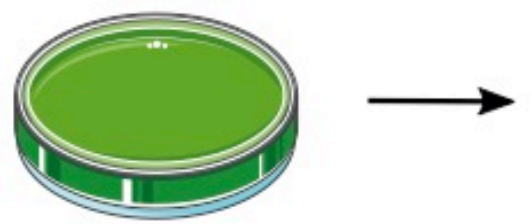

48H REVERTING

CELLS

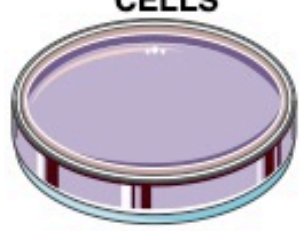

\section{$?$}

\section{Differentiation time line}

Figure 1: Experimental design.

At $0 \mathrm{H}$, cells grown in self-renewal medium are shifted in differentiation medium. $24 \mathrm{H}$ later, the cell population is divided in two, half being kept in differentiation medium and half being grown back into self-renewal medium. At each time point, 192 cells are collected for each subsequent experiment: scRT-qPCR and scRNAseq. 

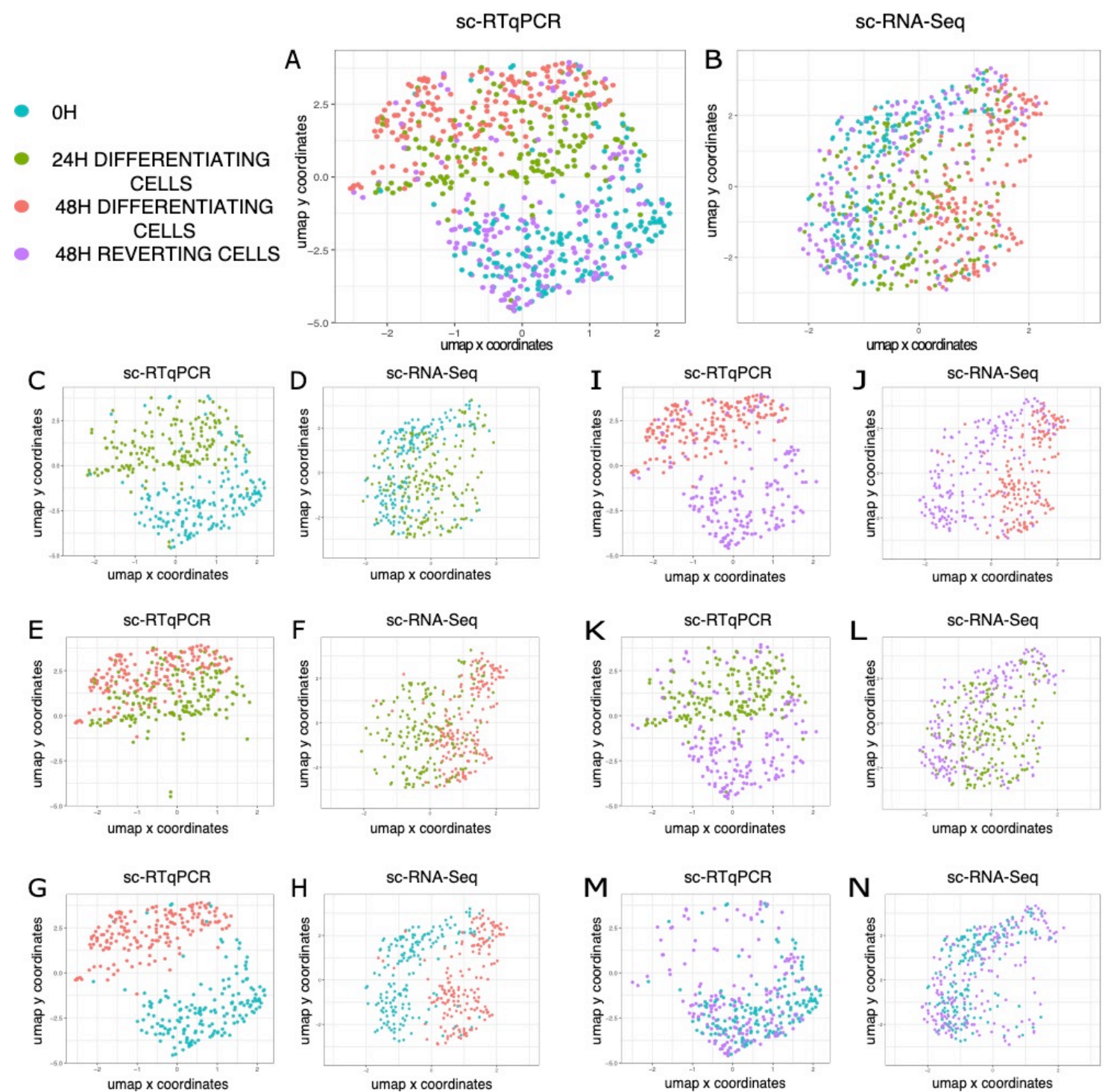

Figure 2: UMAP visualization of scRT-qPCR and scRNAseq data. All UMAPs are calculated using the 4 biological conditions. $0 \mathrm{H}$ cells are displayed in blue, $24 \mathrm{H}$ cells in green, $48 \mathrm{H}$ differentiating cells in red and $48 \mathrm{H}$ reverting cells in purple.

Panels A, C, E, G, I, K and M: scRT-qPCR data

Panels B, D, F, H, J, L and N: scRNAseq data

Panels A and B: all 4 conditions

Panels C and D: $0 \mathrm{H}$ and $24 \mathrm{H}$ differentiating cells

Panels E and F: $24 \mathrm{H}$ and $48 \mathrm{H}$ differentiating cells

Panels $\mathrm{G}$ and $\mathrm{H}: 0 \mathrm{H}$ and $48 \mathrm{H}$ differentiating cells

Panels I and J: 48H differentiating and 48H reverting cells

Panels K and L: $24 \mathrm{H}$ and $48 \mathrm{H}$ reverting cells

Panels $\mathrm{M}$ and $\mathrm{N}$ : $0 \mathrm{H}$ and $48 \mathrm{H}$ reverting cells 

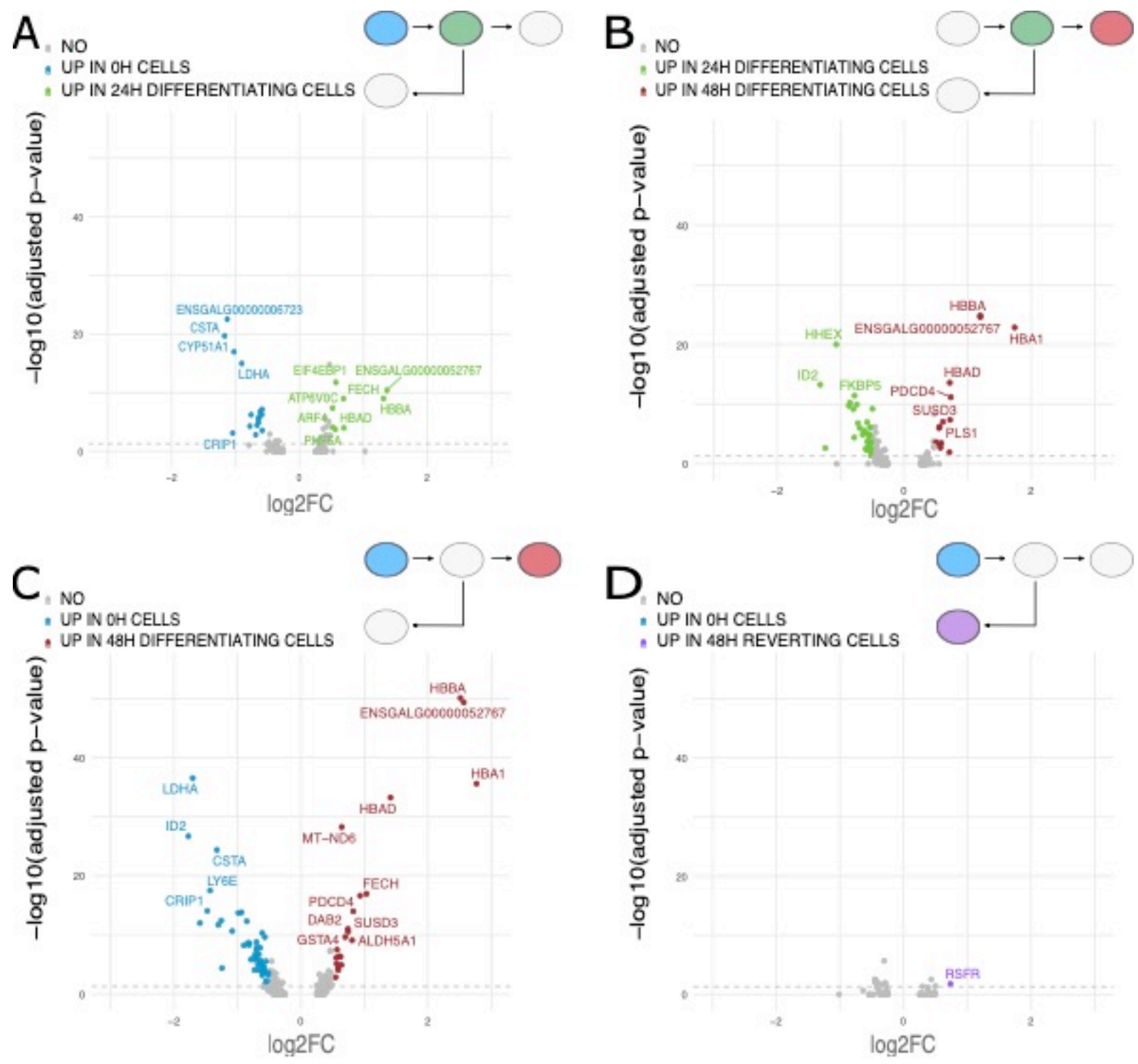

" UP IN OH CELLS
UP IN 48 H REVERTING CELLS
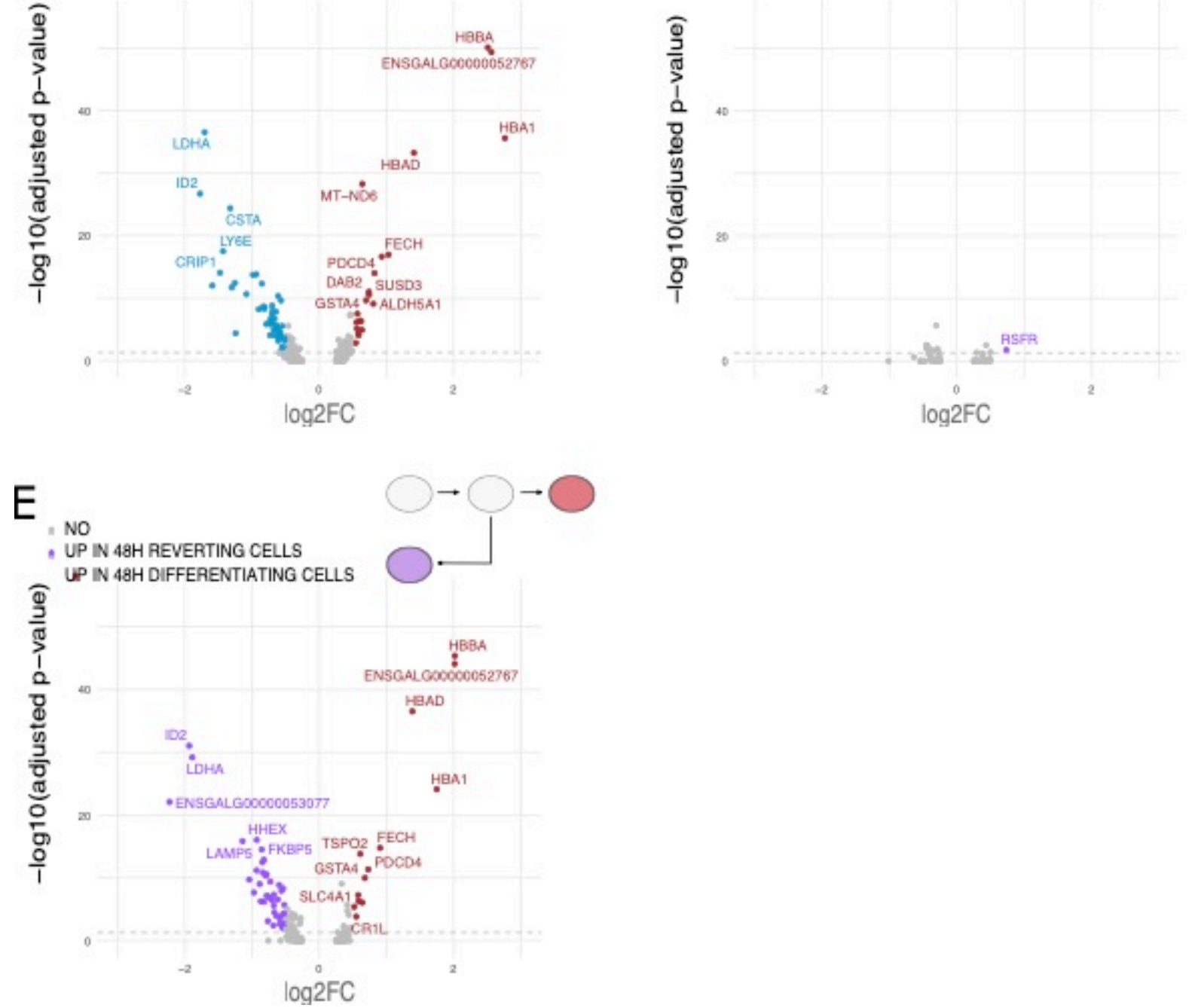

Figure 3: Volcano plot of genes from scRNAseq data differentially expressed between conditions analyzed two by two. Genes are considered significantly differentially expressed 
when the fold change is equal or above 0,5 and adjusted p-value is below 0,05 (grey dotted line).

Panel A: $\mathrm{OH}$ and $24 \mathrm{H}$ differentiating cells. Blue dots represent significantly up-regulated genes in $\mathrm{OH}$ condition and green dots represent significantly up-regulated genes in $24 \mathrm{H}$ condition.

Panel B: $24 \mathrm{H}$ differentiating and $48 \mathrm{H}$ differentiating cells. Green dots represent significantly up-regulated genes in $24 \mathrm{H}$ differentiating cells and red dots represent significantly upregulated genes in $48 \mathrm{H}$ differentiating cells.

Panel C: $\mathrm{OH}$ and $48 \mathrm{H}$ differentiating cells. Blue dots represent significantly up-regulated genes in $\mathrm{OH}$ cells and red dots represent significantly up-regulated genes in $48 \mathrm{H}$ differentiating cells.

Panel D: $\mathrm{OH}$ and $48 \mathrm{H}$ reverting cells. Blue dots represent significantly up-regulated genes in $\mathrm{OH}$ cells and purple dots represent significantly up-regulated genes in $48 \mathrm{H}$ reverting cells.

Panel E: $48 \mathrm{H}$ reverting and $48 \mathrm{H}$ differentiating cells. Purple dots represent significantly upregulated genes in $48 \mathrm{H}$ reverting cells and red dots represent significantly up-regulated genes in $48 \mathrm{H}$ differentiating cells. 

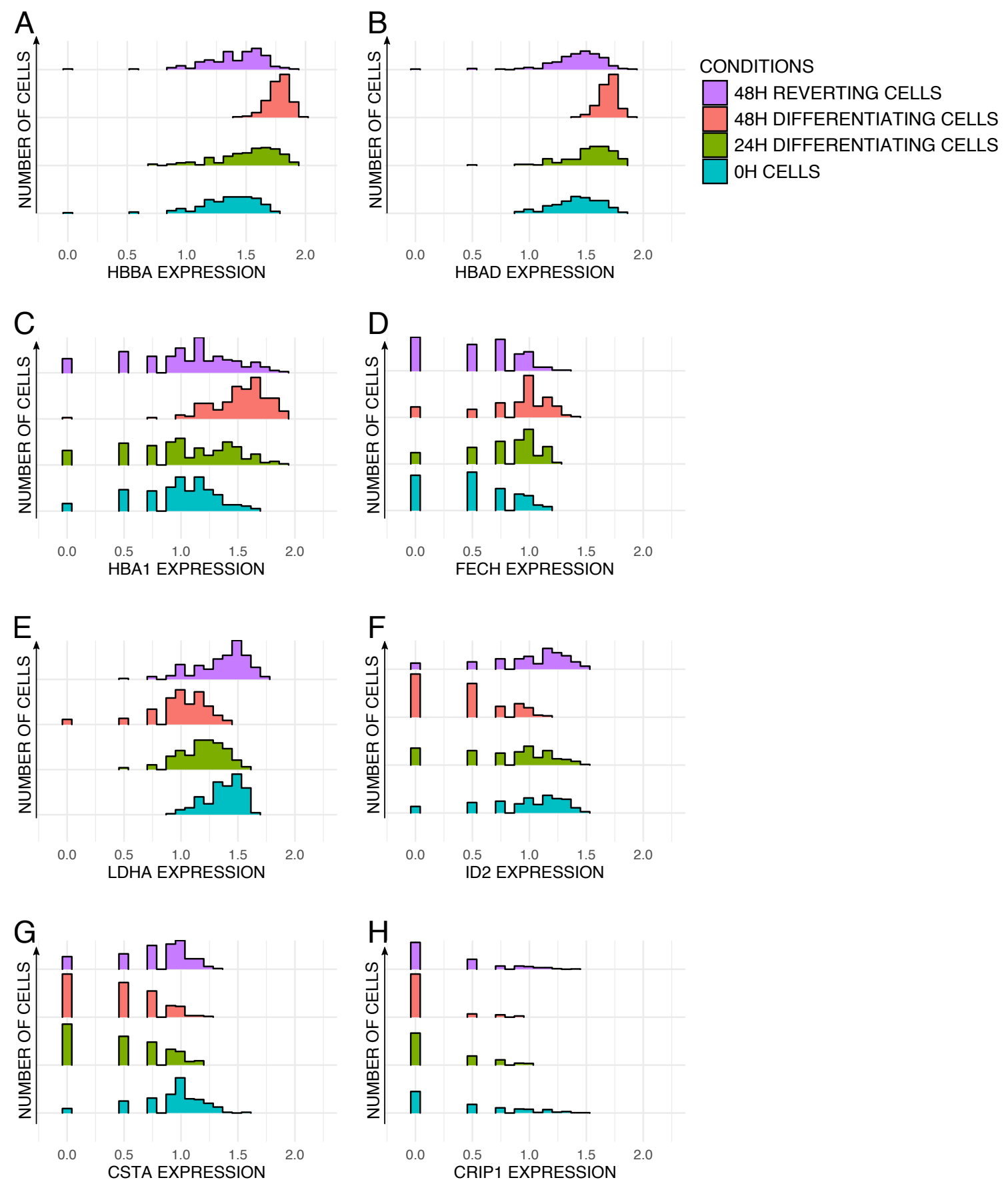

Figure 4: Comparison of gene expression pattern distributions between cells at four experimental time-points $(0 \mathrm{H}, 24 \mathrm{H}, 48 \mathrm{H}$ differentiating and $48 \mathrm{H}$ reverting cells). $\mathrm{X}$ scale represents $\log 1 \mathrm{p}$ of gene expression from scRNAseq data.

Color legend: undifferentiated cells ( $0 \mathrm{H}$ in blue), $24 \mathrm{H}$ differentiating cells (in green), 48H differentiating cells (in red) and $48 \mathrm{H}$ reverting cells (in purple).

Histograms of gene expression distribution for $H B B A$ (Panel A), for HBAD (Panel B), for HBA1 (Panel C), for FECH (Panel D), for LDHA (Panel E), for ID2 (Panel F), for CSTA (Panel G) and for CRIP1 (Panel H). 
bioRxiv preprint doi: https://doi.org/10.1101/2022.02.01.478637; this version posted February 3, 2022. The copyright holder for this preprint (which was not certified by peer review) is the author/funder, who has granted bioRxiv a license to display the preprint in perpetuity. It is made available under aCC-BY-NC-ND 4.0 International license.

A Wasserstein distance comparison between $48 \mathrm{H}$ differentiating and $48 \mathrm{H}$ reverting cells for each gene distribution

Measure of distance dispersion using Gini index

Gene A

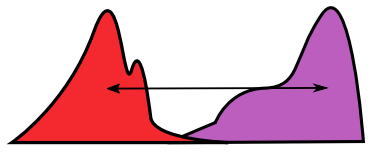

Gene B
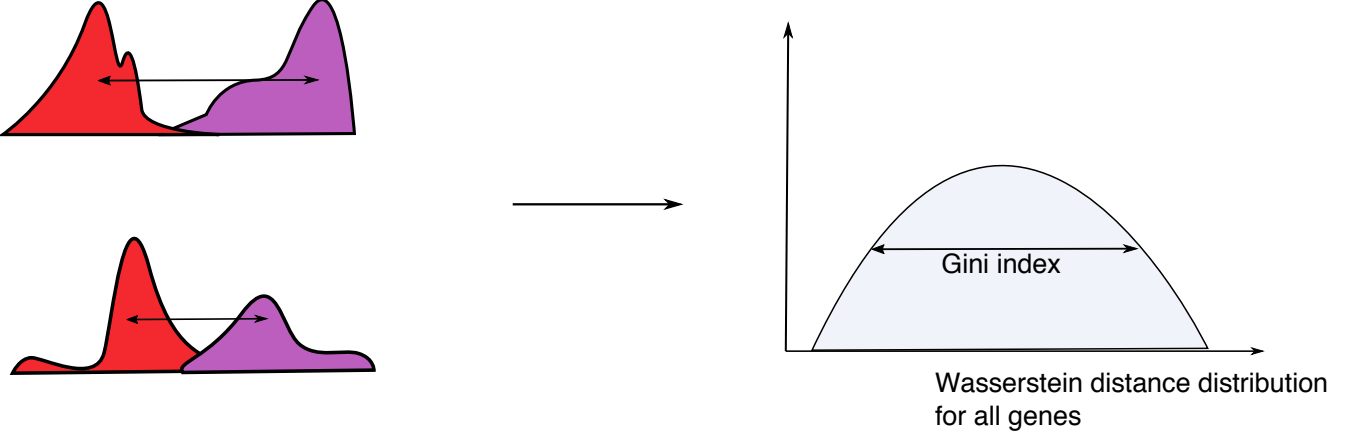

Wasserstein distance comparison between $\mathrm{OH}$ and $48 \mathrm{H}$ reverting cells for each gene distribution

Gene A

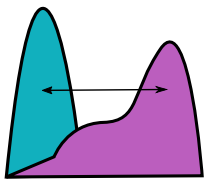

Gene B

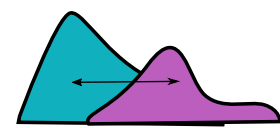

Measure of distance dispersion using Gini index

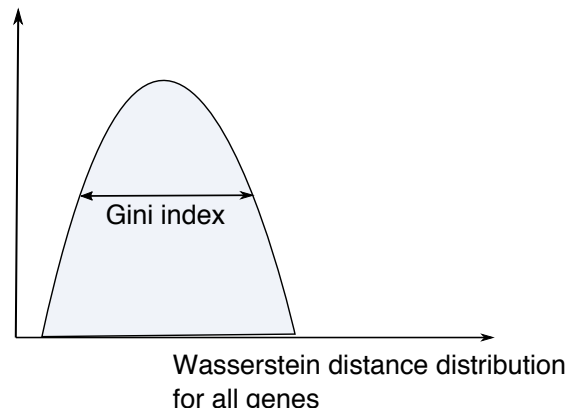

B

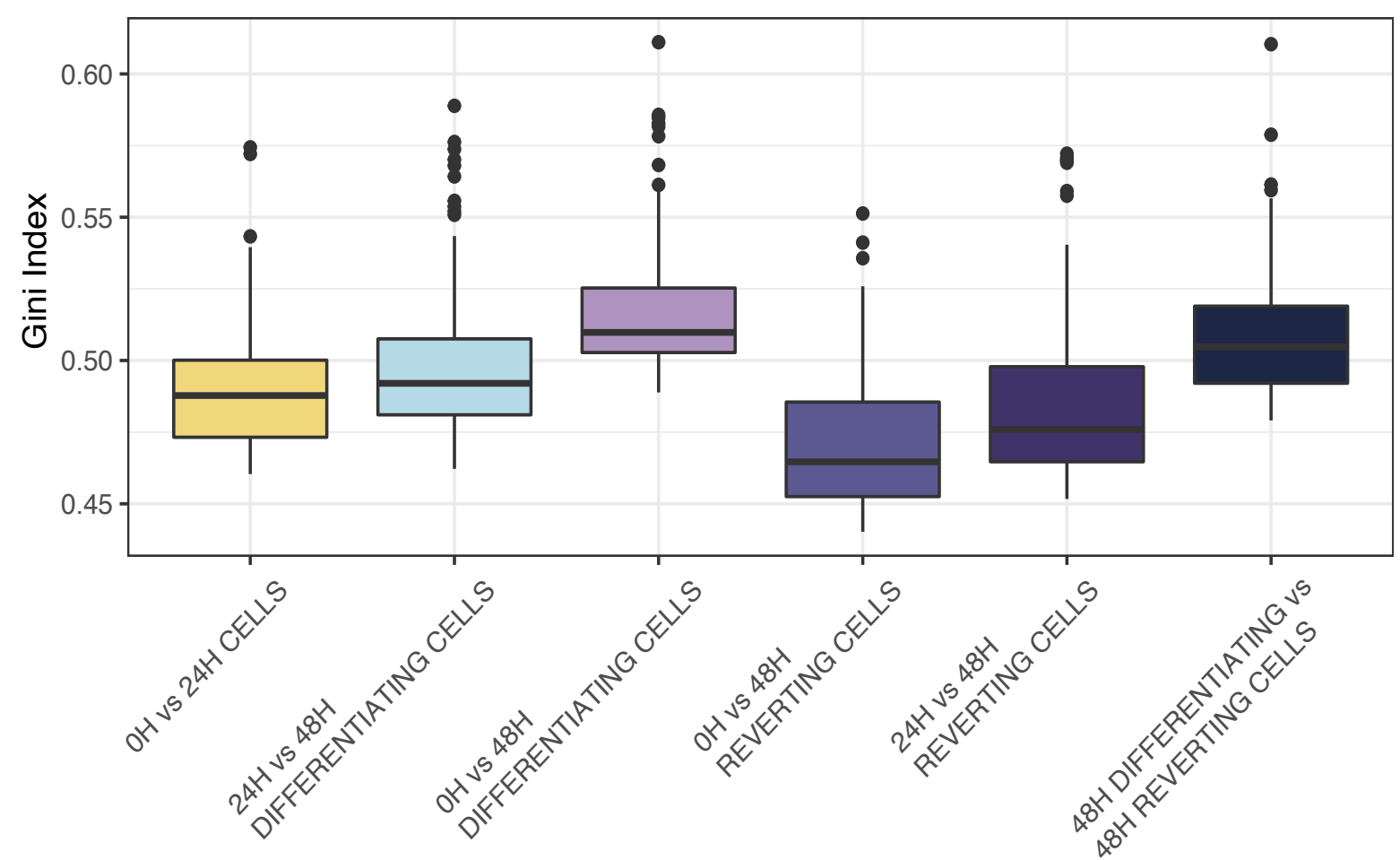

Figure 5: Comparison of dispersion of gene distribution between cell populations. 
Panel A: Experiment design to compare gene distributions between the 4 biological conditions. Wasserstein distance is computed for each gene between pair of conditions, then dispersion of all gene distributions is calculated using Gini index.

Panel B: Plot of Gini index values of Wasserstein distance distributions between conditions in pairs computed for each of the 2000 genes from scRNAseq data bootstraped 100 times. 
A

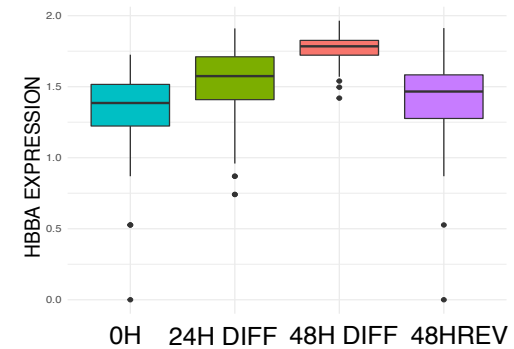

B

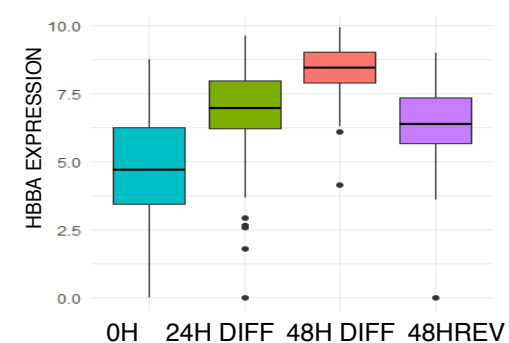

C

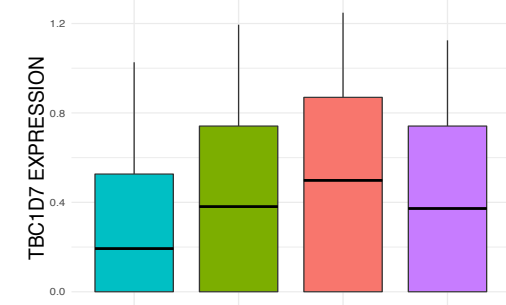

OH $24 \mathrm{H} \mathrm{DIFF} \mathrm{48H} \mathrm{DIFF} \mathrm{48HREV}$
$\mathrm{E}$

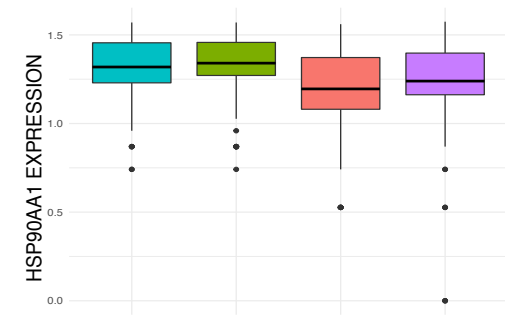

OH $24 \mathrm{H}$ DIFF $48 \mathrm{H}$ DIFF $48 \mathrm{HREV}$

$\mathrm{F}$

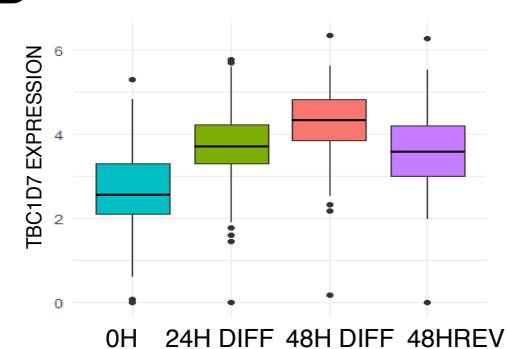

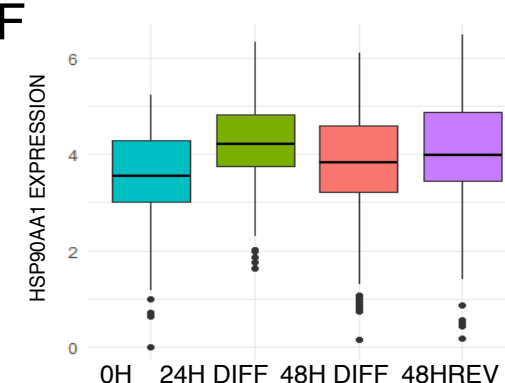

Figure 6: Boxplots with mean of expression levels of the 3 genes identified by Sparse PLS as discriminating genes between $48 \mathrm{H}$ reverting cells and $0 \mathrm{H}$ cells.

Boxplots of $H B B A$ expression level in $\log 1 \mathrm{p}$ on scRNAseq data (panel A) and scRT-qPCR data (panel B) in the 4 biological conditions.

Boxplots of TBC1D7 expression level in $\log 1 \mathrm{p}$ on scRNAseq data (panel C) and scRTqPCR data (panel D) in the 4 biological conditions.

Boxplots of HSP90AA1 expression level in $\log 1 \mathrm{p}$ on scRNAseq data (panel E) and scRTqPCR data (panel F) in the 4 biological conditions. 
A
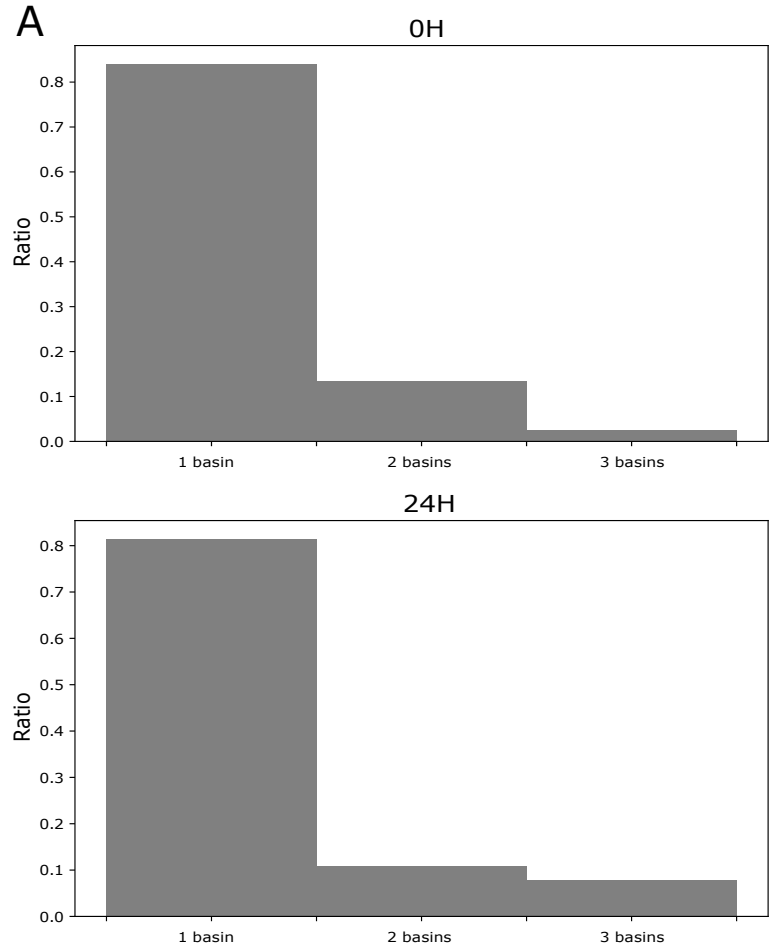

48H DIFFERENTIATING

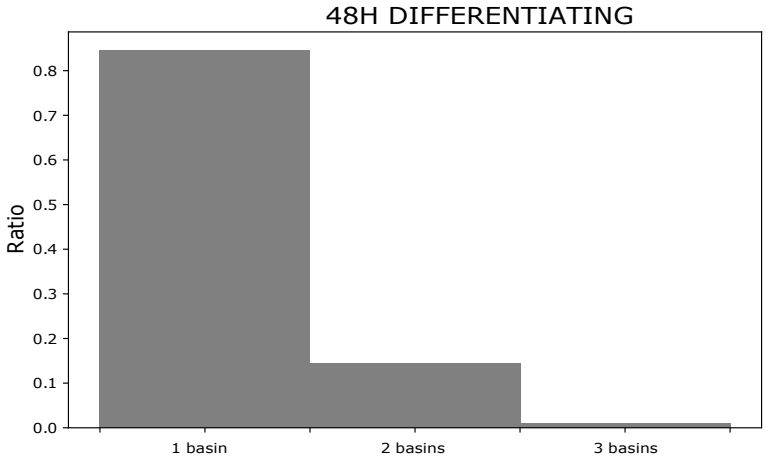

48H REVERTING

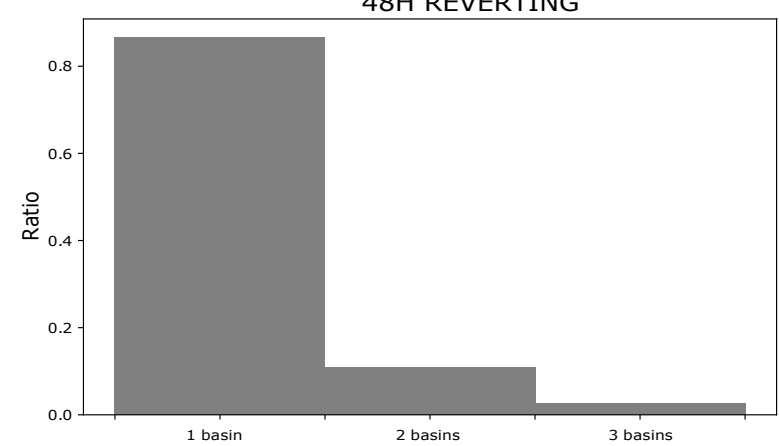

B
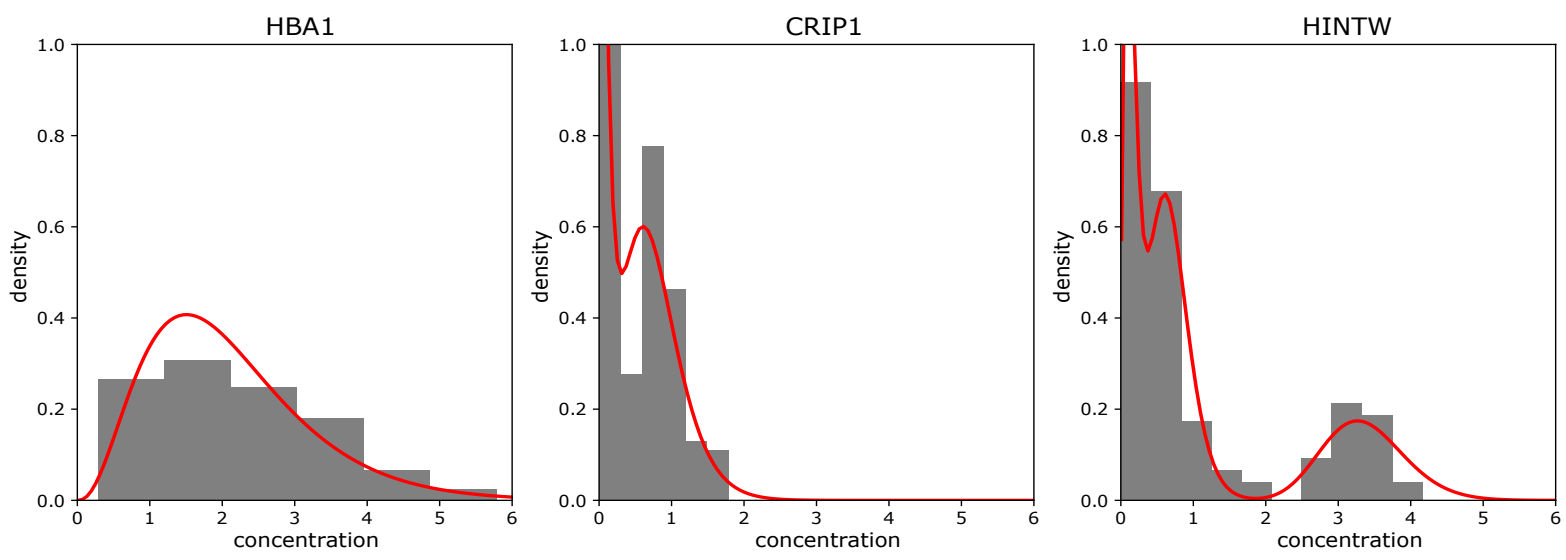

Figure 7: The repartition in the number of basins which have been detected for the 200 most variables genes from scRNAseq data, characterizing the level of multi-stability which is observed for each condition.

Panel A: Repartition of the number of modes for each biological condition.

Panel B: Examples of genes which distribution fits 1 basin (left), 2 basins (middle) or 3 basins (right). 


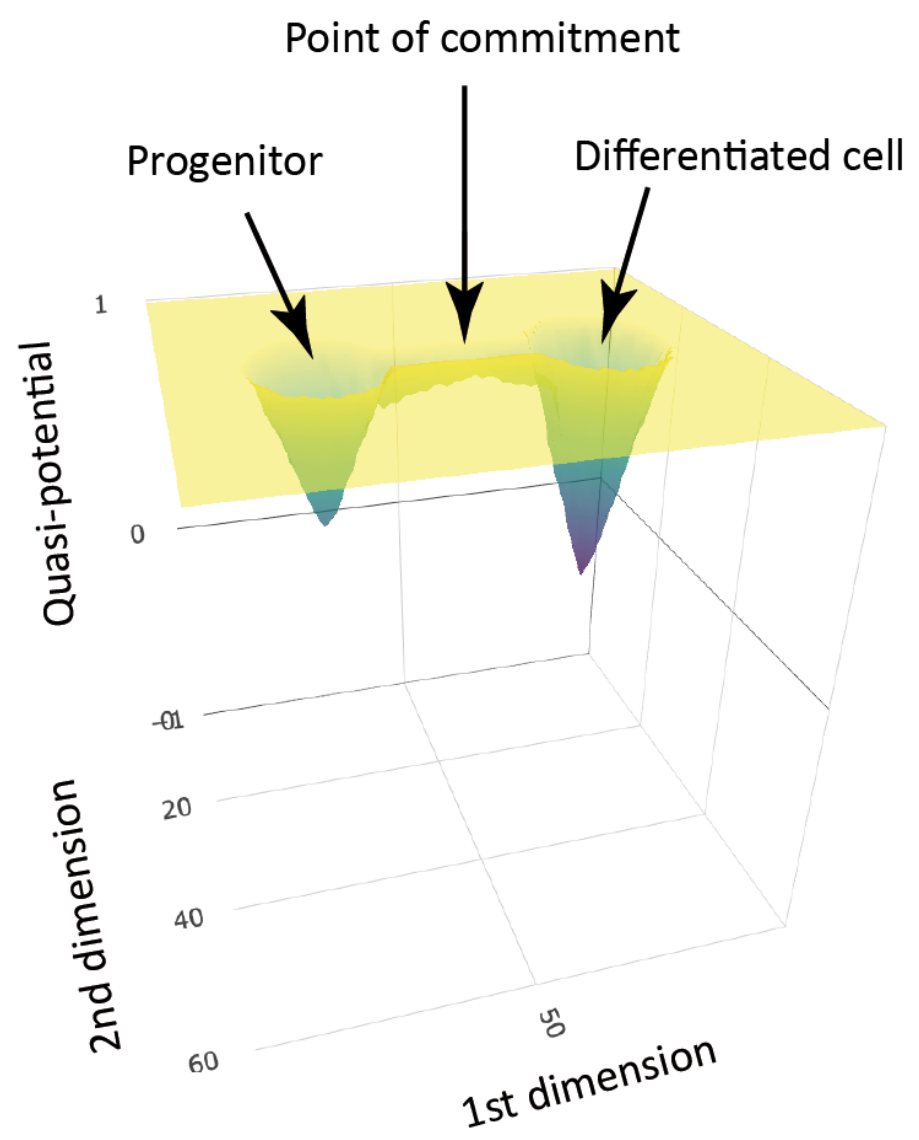

Figure 8: A quasi-potential well depictions of the erythroid differentiation process. While the cells have not escaped the zone of influence of the progenitor attractor (i.e. when they have not passed the point of commitment, aka the point of no return (19)) the removal of the environmental influences results in their relaxing back to their original attractor state. 
bioRxiv preprint doi: https://doi.org/10.1101/2022.02.01.478637; this version posted February 3, 2022. The copyright holder for this preprint (which was not certified by peer review) is the author/funder, who has granted bioRxiv a license to display the preprint in perpetuity. It is made available under aCC-BY-NC-ND 4.0 International license.

\begin{tabular}{|l|l|l|l|}
\hline & OH vs $48 \mathrm{H}$ reverting & OH vs $48 \mathrm{H}$ differentiating & $\begin{array}{l}48 \mathrm{H} \text { reverting vs } 48 \mathrm{H} \\
\text { differentiating }\end{array}$ \\
\hline $\begin{array}{l}\mathrm{p}- \\
\text { value }\end{array}$ & 1.00 & 0 & 0.00000000369 \\
\hline
\end{tabular}

Table 1: P-values output of multivariate two tests between pair of conditions compared. 


\section{Acknowledgements}

We gratefully thank all members of SBDM team and particularly Gerard Benoit for very fruitfull discussions, suggestions and commentaries on our project. We also thank Ghislain Durif for his great technical support during PLS computation and G. Yvert for helpful comments about the manuscript. We thank the computational center of IN2P3 (Villeurbanne/France) and Pôle Scientifique de Modélisation Numérique (PSMN, Ecole Normale Supérieure de Lyon) where computations were performed. We aknowledge the contribution of the AniRA-Cytométrie core facility of SFR BioSciences (UAR3444/US8). We thank the BioSyL Federation and the LabEx Ecofect (ANR-11-LABX-0048) of the University of Lyon for inspiring scientific events.

\section{Funding}

This work was supported by funding from the French agency ANR (SinCity; ANR-17CE12-0031) and the Association Nationale de la Recherche Technique (ANRT, CIFRE 2020/1037). 


\section{References}

1. Wolpert L. Do we understand development? Science. 1994 Oct 28;266(5185):571-2.

2. Elowitz MB. Stochastic Gene Expression in a Single Cell. Science. 2002 Aug 16;297(5584):1183-6.

3. Ozbudak EM, Thattai M, Kurtser I, Grossman AD, van Oudenaarden A. Regulation of noise in the expression of a single gene. Nat Genet. 2002 May;31(1):69-73.

4. Symmons 0, Raj A. What's Luck Got to Do with It: Single Cells, Multiple Fates, and Biological Nondeterminism. Mol Cell. 2016 Jun;62(5):788-802.

5. Kolodziejczyk AA, Lönnberg T. Global and targeted approaches to single-cell transcriptome characterization. Brief Funct Genomics. 2018 Jul 1;17(4):209-19.

6. Kalmar T, Lim C, Hayward P, Muñoz-Descalzo S, Nichols J, Garcia-Ojalvo J, et al. Regulated Fluctuations in Nanog Expression Mediate Cell Fate Decisions in Embryonic Stem Cells. Goodell MA, editor. PLoS Biol. 2009 Jul 7;7(7):e1000149.

7. Blake WJ, Balázsi G, Kohanski MA, Isaacs FJ, Murphy KF, Kuang Y, et al. Phenotypic Consequences of Promoter-Mediated Transcriptional Noise. Mol Cell. 2006 Dec;24(6):853-65.

8. Waddington, C.H. The Strategy of the Genes [Internet]. 1st ed. Routledge; 1957. Available from: https://doi.org/10.4324/9781315765471

9. Shi J, Teschendorff AE, Chen W, Chen L, Li T. Quantifying Waddington's epigenetic landscape: a comparison of single-cell potency measures. Brief Bioinform. 2018;5.

10. Moris N, Pina C, Arias AM. Transition states and cell fate decisions in epigenetic landscapes. Nat Rev Genet. 2016 Nov;17(11):693-703.

11. Baron, Margaret H. Reversibility of the differentiated state in somatic cells. Curr Opin Cell Biol. 1993;5(6):1050-6.

12. Rajagopal J, Stanger BZ. Plasticity in the Adult: How Should the Waddington Diagram Be Applied to Regenerating Tissues? Dev Cell. 2016 Jan;36(2):133-7.

13. Johnson NC, Dillard ME, Baluk P, McDonald DM, Harvey NL, Frase SL, et al. Lymphatic endothelial cell identity is reversible and its maintenance requires Prox1 activity. Genes Dev. 2008 Nov 17;22(23):3282-91.

14. Ladewig J, Koch P, Brüstle O. Leveling Waddington: the emergence of direct programming and the loss of cell fate hierarchies. Nat Rev Mol Cell Biol. 2013 Apr;14(4):225-36.

15. Zalc A, Sinha R, Gulati GS, Wesche DJ, Daszczuk P, Swigut T, et al. Reactivation of the pluripotency program precedes formation of the cranial neural crest. Science. 2021 Feb 5;371(6529):eabb4776.

16. Buczacki SJA, Zecchini HI, Nicholson AM, Russell R, Vermeulen L, Kemp R, et al. Intestinal label-retaining cells are secretory precursors expressing Lgr5. Nature. 2013 Mar;495(7439):65-9.

17. Tata PR, Mou H, Pardo-Saganta A, Zhao R, Prabhu M, Law BM, et al.

Dedifferentiation of committed epithelial cells into stem cells in vivo. Nature. 2013 Nov 14;503(7475):218-23.

18. Chang HH, Hemberg M, Barahona M, Ingber DE, Huang S. Transcriptome-wide noise controls lineage choice in mammalian progenitor cells. Nature. 2008 May;453(7194):544-7.

19. Richard A, Boullu L, Herbach U, Bonnafoux A, Morin V, Vallin E, et al. Single-CellBased Analysis Highlights a Surge in Cell-to-Cell Molecular Variability Preceding Irreversible Commitment in a Differentiation Process. Teichmann SA, editor. PLOS Biol. 2016 Dec 27;14(12):e1002585. 
20. Lê Cao K-A, Rossouw D, Robert-Granié C, Besse P. A Sparse PLS for Variable Selection when Integrating Omics Data. Stat Appl Genet Mol Biol [Internet]. 2008 Jan 18 [cited 2021 Jun 8];7(1). Available from:

https://www.degruyter.com/document/doi/10.2202/1544-6115.1390/html

21. Mojtahedi M, Skupin A, Zhou J, Castaño IG, Leong-Quong RYY, Chang H, et al. Cell Fate Decision as High-Dimensional Critical State Transition. PLoS Biol. 2016 Dec 27;14(12):e2000640.

22. Jaitin DA, Kenigsberg E, Keren-Shaul H, Elefant N, Paul F, Zaretsky I, et al. Massively Parallel Single-Cell RNA-Seq for Marker-Free Decomposition of Tissues into Cell Types. Science. 2014 Feb 14;343(6172):776-9.

23. Secchi P, Stamm A, Vantini S. Inference for the mean of large $\$ p \$$ small $\$ n \$$ data: A finite-sample high-dimensional generalization of Hotelling's theorem. Electron J Stat [Internet]. 2013 Jan 1 [cited 2021 Dec 10];7(none). Available from: https://projecteuclid.org/journals/electronic-journal-of-statistics/volume-7/issuenone/Inference-for-the-mean-of-large-p-small-n-data/10.1214/13-EJS833.full 24. Richard A, Vallin E, Romestaing C, Roussel D, Gandrillon 0, Gonin-Giraud S. Erythroid differentiation displays a peak of energy consumption concomitant with glycolytic metabolism rearrangements. PLOS ONE. 2019 Sep 4;14(9):e0221472. 25. Yokota Y, Mori S, Narumi O, Kitajima K. In vivo function of a differentiation inhibitor, Id2. IUBMB Life. 2001 Apr;51(4):207-14.

26. Klenova EM, Botezato I, Laudet V, Goodwin GH, Wallace JC, Lobanenkov VV. Isolation of a cDNA clone encoding the RNASE-superfamily-related gene highly expressed in chicken bone marrow cells. Biochem Biophys Res Commun. 1992 May;185(1):231-9.

27. Dibble CC, Elis W, Menon S, Qin W, Klekota J, Asara JM, et al. TBC1D7 Is a Third Subunit of the TSC1-TSC2 Complex Upstream of mTORC1. Mol Cell. 2012 Aug;47(4):535-46.

28. Zuehlke AD, Beebe K, Neckers L, Prince T. Regulation and function of the human HSP90AA1 gene. Gene. 2015 Oct;570(1):8-16.

29. Bonnaffoux A, Herbach U, Richard A, Guillemin A, Gonin-Giraud S, Gros P-A, et al. WASABI: a dynamic iterative framework for gene regulatory network inference. BMC Bioinformatics. 2019 Dec;20(1):220.

30. Nichols JM, Antolović V, Reich JD, Brameyer S, Paschke P, Chubb JR. Cell and molecular transitions during efficient dedifferentiation. eLife. 2020 Apr 7;9:e55435.

31. Blau HM. Differentiation requires continuous active control. Annu Rev Biochem. 1992;61:1213-30.

32. Johnson NC, Dillard ME, Baluk P, McDonald DM, Harvey NL, Frase SL, et al. Lymphatic endothelial cell identity is reversible and its maintenance requires Prox1 activity. Genes Dev. 2008 Dec 1;22(23):3282-91.

33. Sokolik C, Liu Y, Bauer D, McPherson J, Broeker M, Heimberg G, et al.

Transcription Factor Competition Allows Embryonic Stem Cells to Distinguish Authentic Signals from Noise. Cell Syst. 2015 Aug;1(2):117-29.

34. Thankamony AP, Saxena K, Murali R, Jolly MK, Nair R. Cancer Stem Cell Plasticity - A Deadly Deal. Front Mol Biosci. 2020 Apr 30;7:79.

35. Kimmel JC, Yi N, Roy M, Hendrickson DG, Kelley DR. Differentiation reveals latent features of aging and an energy barrier in murine myogenesis. Cell Rep. 2021 Apr;35(4):109046.

36. Guillemin A, Stumpf MPH. Noise and the molecular processes underlying cell fate decision-making. Phys Biol. 2021 Jan 7;18(1):011002. 
37. Pisco AO, Fouquier d'Hérouël A, Huang S. Conceptual Confusion: The case of Epigenetics [Internet]. Systems Biology; 2016 May [cited 2021 Sep 1]. Available from: http://biorxiv.org/lookup/doi/10.1101/053009

38. Ventre E, Espinasse T, Bréhier C-E, Calvez V, Lepoutre T, Gandrillon O. Reduction of a stochastic model of gene expression: Lagrangian dynamics gives access to basins of attraction as cell types and metastabilty. J Math Biol. 2021 Nov;83(5):59.

39. Huang S. Reprogramming cell fates: reconciling rarity with robustness. BioEssays. 2009 May;31(5):546-60.

40. Ventre E, Espinasse T, Bréhier C-E, Calvez V, Lepoutre T, Gandrillon O. Reduction of a stochastic model of gene expression: Lagrangian dynamics gives access to basins of attraction as cell types and metastabilty [Internet]. Systems Biology; 2020 Sep [cited 2021 Sep 1]. Available from:

http://biorxiv.org/lookup/doi/10.1101/2020.09.04.283176

41. Sáez M, Blassberg R, Camacho-Aguilar E, Siggia ED, Rand DA, Briscoe J.

Statistically derived geometrical landscapes capture principles of decision-making dynamics during cell fate transitions. Cell Syst. 2022 Jan;13(1):12-28.e3.

42. Rajagopal J, Stanger BZ. Plasticity in the Adult: How Should the Waddington Diagram Be Applied to Regenerating Tissues? Dev Cell. 2016 Jan 25;36(2):133-7.

43. Moussy A, Cosette J, Parmentier R, da Silva C, Corre G, Richard A, et al. Integrated time-lapse and single-cell transcription studies highlight the variable and dynamic nature of human hematopoietic cell fate commitment. Huang S, editor. PLOS Biol. 2017 Jul 27;15(7):e2001867.

44. Gandrillon O, Schmidt U, Beug H, Samarut J. TGF- $\beta$ cooperates with TGF- $\alpha$ to induce the self-renewal of normal erythrocytic progenitors: evidence for an autocrine mechanism. EMBO J. 1999 May 17;18(10):2764-81.

45. Gandrillon 0, Samarut J. Role of the different RAR isoforms in controlling the erythrocytic differentiation sequence. Interference with the v-erbA and p135gag-mybets nuclear oncogenes. Oncogene. 1998 Feb 5;16(5):563-74.

46. Nextflow - A DSL for parallel and scalable computational pipelines [Internet]. [cited 2021 Sep 24]. Available from: https://www.nextflow.io./

47. Team R. A language and environment for statistical computing. Computing. 2006 Jan $1 ; 1$.

48. Cole MB, Risso D, Wagner A, DeTomaso D, Ngai J, Purdom E, et al. Performance Assessment and Selection of Normalization Procedures for Single-Cell RNA-Seq. Cell Syst. 2019 Apr;8(4):315-328.e8.

49. Hafemeister C, Satija R. Normalization and variance stabilization of single-cell RNA-seq data using regularized negative binomial regression [Internet]. Genomics; 2019 Mar [cited 2021 Jan 11]. Available from:

http://biorxiv.org/lookup/doi/10.1101/576827

50. Stuart T, Butler A, Hoffman P, Hafemeister C, Papalexi E, Mauck WM, et al. Comprehensive integration of single cell data [Internet]. Genomics; 2018 Nov [cited 2019 Nov 20]. Available from: http://biorxiv.org/lookup/doi/10.1101/460147

51. Becht E, McInnes L, Healy J, Dutertre C-A, Kwok IWH, Ng LG, et al. Dimensionality reduction for visualizing single-cell data using UMAP. Nat Biotechnol. 2018 Dec 3;37(1):38-44.

52. Schuhmacher D, Bähre B, Gottschlich C, Hartmann V, Heinemann F, Schmitzer B. transport: Computation of Optimal Transport Plans and Wasserstein Distances. $\mathrm{R}$ package version 0.12-2 [Internet]. 2020. Available from: https://cran.rproject.org $/$ package $=$ transport 
53. Zeileis A. ineq: Measuring Inequality, Concentration, and Poverty [Internet]. 2014. Available from: https://CRAN.R-project.org/package=ineq

54. Hadley Wickham, Romain François, Lionel Henry, Kirill Müller. dplyr: A Grammar of Data Manipulation [Internet]. 2021. Available from: https://dplyr.tidyverse.org, https://github.com/tidyverse/dplyr

55. Albayrak C, Jordi CA, Zechner C, Lin J, Bichsel CA, Khammash M, et al. Digital Quantification of Proteins and mRNA in Single Mammalian Cells. Mol Cell. 2016 Mar;61(6):914-24.

56. Peccoud J, Ycart B. Markovian Modeling of Gene-Product Synthesis. Theoretical Population Biology. Volume 48, Issue 2. 1995;222-34.

57. Ventre E. Reverse engineering of a mechanistic model of gene expression using metastability and temporal dynamics. :25.

58. Benjamini Y, Hochberg Y. Controlling the False Discovery Rate: A Practical and Powerful Approach to Multiple Testing. J R Stat Soc Ser B Methodol. 1995 Jan;57(1):289-300.

59. Stamm A, Pini A, Vantini S. fdahotelling: Inference for Functional Data Analysis in $\mathrm{R}$ [Internet]. Available from: https://mox.polimi.it/publicationresults/?id=524\&tipo=add_qmox, http://projecteuclid.org/euclid.ejs/1375708877 